\title{
Life cycle assessment (LCA) of sustainable building materials: an
} overview

\author{
Grace K. C. Ding, University of Technology Sydney, Australia
}

\begin{abstract}
The construction industry is one of the largest exploiters of both renewable and nonrenewable natural resources. It was inevitable that it had found itself at the centre of concerns regarding environmental impact. The process and operation of building construction consumes a great deal of materials throughout its service life cycle. The selection and use of sustainable building materials play an important role in the design and construction of green building. This chapter set out to present an overview of sustainable building materials and their impacts on the environment. It also discusses the life cycle assessment as a methodological principle and framework, and its limitations for the analysis of sustainable building materials.
\end{abstract}

Keywords: green building materials, LCA, Sustainable construction, sustainable development

\subsection{Introduction}

Environmental economics and sustainable development have become central concerns to people from all disciplines and in all countries (Cole, 1999). Many environmental discussions centre on the concept of ecologically sustainable development (ESD) since the major oil crisis of the 1970s (Balderstone, 2004). ESD, from a building development viewpoint, is the efficient use of resources to meet the requirements and needs of present and future generations whilst minimizing the adverse effects on the natural environment.

Buildings have a direct impact on the environment, ranging from the use of raw materials during construction, maintenance and renovation to the emission of harmful substances throughout the building's life cycle (Balaras et al., 2005). The construction industry and the environment are inextricably linked. It was inevitable that the industry had found itself at the centre of concerns regarding environmental impact. Environmental problems associated with resource consumption have been extended from the local scale of indoor air pollution to a global scale of contribution to climate change and ozone depletion.

Construction is not an environmentally friendly process and it has major impacts on the depletion of natural resources and on the emissions of greenhouse gas (GHG) as a result of fossil fuel combustion. In the US, the construction sector is the third largest industry sector in terms of contributions to GHG emissions ( $\mathrm{Li}$ et al., 2010). Globally, it depletes $40 \%$ of natural materials, consumes $40 \%$ of the total primary energy, $15 \%$ of the world's fresh water resources, generates $25 \%$ of all wastes and emits $40-50 \%$ of GHG (Ramesh et al., 2010; Mokhelsian \& Holmen, 2012).

To minimize the industry's environmental impacts, the use of sustainable building materials has become the main focus of research and development in achieving the goal of sustainable construction. This is one way in which the construction industry can make a responsible contribution towards protecting the environment (Du Plessis, 2007). Achieving the goal of sustainable construction is not about restricting the total amount of construction, but to pay more attention on how the design and selection of sustainable building materials can complement the 
environment to improve living quality, user health and comfort. The selection of sustainable building materials should not only focus on the performance specifications but also select materials that have the lowest GHG emissions (Ip \& Miller, 2012).

Ecological building design is characterised with the use of natural materials rather than manmade materials that require energy in the process, and has an emphasis on healthy, non-toxic specification that minimize pollution (Halliday, 2008). Ideally materials should also be implemented into passive design and environment control such as thermal mass. Berge (2009) states that an acceptable goal of achieving a sustainable future is the drastic reduction and shift in the use of raw materials. This is particularly important when considering scarce and nonrenewable resources. Equally important is the reduction of wastage and losses during the manufacture of materials, the construction process and also throughout the service life of the completed building. The recycling of materials during demolition of a building must also become regulated. The recycling process should be carefully planned and managed to ensure that these materials can be taken care of, maintaining them to the original quality rather than being disposed of.

This chapter aims at reviewing impacts of building materials on the environment and the importance of sustainable building materials in enhancing the goal of sustainable construction for the design and construction of green building. This chapter presents the methodological principle and framework of the life cycle assessment (LCA) for the analysis of sustainable building materials. The chapter reviews LCA tools, studies and concludes with limitations of the LCA method.

\subsection{Environmental impacts of building materials}

\subsubsection{Sustainable building materials}

The building and construction industry consumes great quantities of raw materials and energy. According to Bribian et al. (2011) approximately $24 \%$ of global raw materials were consumed by the industry. Traditional building materials including steel, concrete, aluminium and glass are high energy content materials. Buildings impact on the environment during their whole life cycle and the choice of materials used will impact on their overall performance. They are used in various stages, from initial construction through to the operation stage when the buildings are maintained and refurbished to preserve their normal functioning until the end of their service life. Therefore, it is an area that designers can have significant inputs if they are properly informed in the area of incorporating sustainable building materials into the design of the building.

According to Franzoni (2011) the selection of building materials plays an important role in achieving the goal of sustainable development in the construction industry. Choosing materials with high contents of embodied energy entails an initial high level of energy consumption in the production process, which associated with high levels of GHG emissions (Bribian et al., 2011). With the implementation of energy efficient design, the initial embodied energy of building materials becomes a more important consideration (Thormark, 2006). Thormark (2006) further states that more attention should be given not only to the operating energy of a building but also to the material choice. However, according to Saghafi and Teshnizi (2011) the selection of sustainable building materials for a building is the most difficult and challenging task. It is beyond the time and skill of the project team to incorporate environmental aspects of building materials and construction technologies. The process will involve analysing and developing 
environmental profiles of building materials and their interaction with the environment. This is an area that is largely unknown due to the high level of variables and variations.

There are a number of research studies addressing the problems with materials selection. However, most of these studies have failed to properly and adequately establish the definition for 'sustainable building materials'. Up until today there is no universally accepted definition for 'sustainable building materials' (Franzoni, 2011; Saghafi \& Teshnizi, 2011). This makes it very difficult to establish principles and guidelines that enable sustainable building materials to align with the principles and goals of sustainable development in construction.

Sustainable building materials are often regarded as materials that are natural and offer specific benefits to the users in terms of low maintenance, energy efficiency, the improvement of occupant health and comfort, the increase of productivity whilst being less harmful to the environment. However, according to Franzoni (2011) natural materials are not necessary green materials such as asbestos, radon and turpentine. They are natural materials but they are harmful to the built and natural environment in various forms and ways. Therefore, sustainable building materials refer to materials that are environmentally friendly or environmentally responsible materials (Spiegel \& Meadows, 1999; Franzoni, 2011). Accordingly, sustainable building materials dominate with materials that are from renewable sources rather than from the nonrenewable sources. They must also be sustainable during their whole life cycle and requires the use of less energy in the manufacturing process. During the life cycle, these materials must not release pollutants or other emissions that impact on human health and comfort.

\subsubsection{The life cycle impacts of building materials}

Building materials impact on both the built and natural environments throughout their life cycle. According to Franzoni (2011) material selection can take place both at an early stage to establish strategies and undergo market research for sustainable building materials as well as at the design development stage where these materials are incorporated into the design. Esin (2007) states that sustainable building materials should be considered at an early stage and must be evaluated from a life cycle perspective as the decision on material choices will impact the overall performance of the building. The life cycle of building materials is often referred to as a "cradle-to-gate" analysis. The material life cycle relates closely to the pre-use phase of a building and it includes the raw materials extraction, manufacturing process, delivery to the construction site, installation on site, as well as further materials required during the operation stage for maintenance, refurbishment and renovation (Franzoni, 2011).

The raw materials extraction stage relates to the mining and harvesting of raw materials from the natural environment. The extraction process often generates dust, noise, disruption and is a nuisance locally. The process has direct impact on the environment in various ways. It disturbs the immediate natural habitat, flora and fauna, landscape character and causes pollution to the ground and surface water (Halliday, 2008). On the mining site, the work environment has serious impacts on the health and well-being of workers and the people within the vicinity. The process is also usually high in primary energy consumption due to the high level use of machinery and this energy is usually considered a part of the initial embodied energy of the extracted materials.

Raw materials extracted will require a manufacturing process to transform them into usable materials for construction purposes. The process has attracted serious concerns from people from a social and environmental viewpoint. It requires significant inputs of energy and other resources 
in the manufacturing process and usually outputs with solid wastes and other pollutants that may be harmful to the built and natural environment. These outputs can both be toxic and has little or no further usage. This area attracts much attention on how these processes can be improved to be more environmentally and socially friendly. Packaging of building materials for distribution to the building site is also detrimental to the environment as there are few packaging material options that are biodegradable or can be safely burnt (Holliday, 2008). It represents a significant waste of resources and has serious impacts on landfill.

The installation of materials onsite is a process that involves cutting and fitting materials for a building. This process generates waste and construction waste has become a serious environmental problem. The figures generated for construction-related waste are amount to approximately $30 \%$ in the US, $35 \%$ in Canada, $50 \%$ in the UK (Ekanayake \& Ofori, 2004; Esin \& Cosgun, 2007). The waste is often generated due to an inefficient management onsite or workshop and the production of off cuts. Most of this waste can be recycled and reduced if properly planned and managed. The site installation stage also requires energy which will also be considered in the embodied energy calculation.

Most of the construction-related waste is unnecessary according to Sterner (2002) who says that this waste has a high potential for recovery and reuse. However, due to the economic nature of the building industry, every stage of the construction period is kept to a minimal. The depletion of natural resources by the building industry is a topic of serious discussion as much of the recyclable material from building sites end up in landfill sites.

Transportation is often involved in various stages of the life cycle of a material. Transportation is required between the site of extraction, processing/production, and construction. The corresponding accumulation in transport miles associated with the consequent embodied energy and emissions are an area of concern. Smaller and regionally based plants and distribution yards will generally improve the overall environmental burden of a building (Berge, 2009). According to Esin (2007), each stage of the manufacturing process and the final assembly on site requires transportation and the energy consumption can take up to approximately $2.2 \%$ of the life cycle primary energy consumption. Locally sourced and manufactured materials have the potential to make a significant difference to the overall environmental impacts associated with each stage.

During the operation stage of a building, materials are also involved in maintenance, refurbishment and renovation up until the end of the building's service life. The materials used during the operation stage are closely related to the materials selection. Some materials may be high in capital cost and initial embodied energy but have low maintenance requirements. However, other materials may be the other way round. The decision will be subjected to the user and client preferences. The correct choice of materials may not only impact on the maintenance requirements but may also have a harmful effect on occupants and the environment throughout the building life span such as the release of volatile organic compounds (VOCs) and other substances due to chemicals used during the manufacturing process.

End of service life can be discussed from two aspects. It may refer to the end of service life of a particular material where further maintenance may not restore its original function or it may be uneconomical to maintain. The other aspect of end of service life may refer to the entire building even though some of the materials may still be operating and functioning. The eventual replacement and destruction of materials will end up in landfill. The treatments, coatings or preservation that was used may transform natural materials into toxic wastes, dismissed into the 
air and water. Therefore, materials that are recyclable and biodegradable should be selected and used in order to reduce landfill requirements and the release of pollutants.

Building materials are important to be selected not just to serve their intended functions when they are newly installed but also for an acceptable length of time. Some of the building materials may last for the entire life of a building but others may only functional for a few years before renewal. The service life of a material may relate to particular conditions that reflect on the complexity of their chemical and mechanical properties. Natural materials are generally lower in embodied energy intensity and toxicity levels than man-made materials. Products will become sustainable if low embodied energy natural materials are involved (John et al., 2005).

\subsubsection{Sustainable building material selection criteria}

Sustainable building and development involves considering the whole life cycle of buildings that are designed to minimize all adverse impacts on the built and natural environment through sustainable building design and material selection. Building materials selected impact on the environment throughout the life cycle of a building. This life cycle can be divided into five stages including feasibility, design, construction, operation and demolition. Materials are used during the construction stage of a building through to the operation stage which involves building maintenance. The replacing, renewing and renovating of building materials and components remain until the end of service life of the building. Fundamentally, materials play an important role in enhancing the overall performance of a building and in achieving the goal for sustainable construction in the industry.

Buildings are responsible for a substantial amount of material and energy consumption. However, the environmental properties of materials have not traditionally been a design or construction priority (Guggemos \& Horvath, 2005), where the cost, performance characteristics and aesthetics are the main items that determine material selections in buildings (Bayne \& Taylor, 2006). Florez and Castro-Lacouture (2013) in a study for developing an optimization model for sustainable materials selection state that the choice of materials can take place during the feasibility stage when different technological solutions and environmental matters can be incorporated early in the decision-making process.

In most projects, material selection undertakes place at the design development stage when specification and working plans are produced. Indeed selecting appropriate materials for a building is an integral part of good design and the key to good design lies in realizing the importance of occupant health and comfort, and harmonizes it with the inherent properties of materials. Consequently, evaluating the properties of sustainable building materials and their impacts on the environment becomes central to the design and construction of green buildings. As stated by Sturges (1999) designers have gradually turned more attention to material selection and regarded it as an important part of the design. However, it may be at a stage that is either too busy or too late to consider sustainability options of building materials at the design development stage whilst more opportunities may exist if sustainability of building materials can be considered early in a building life cycle.

Methodologies and tools have been developed to optimise material selection in situations where the best combination of physical and mechanical properties is required and this facilitates designers to make objective decisions about material selection (Halliday, 2008). Sturges (1999) suggests using the same principles to optimise material selection by taking into account of 
environmental considerations and focusing on achieving the set sustainability goals to minimize impacts on the environment. This methodological framework usually takes a life cycle approach in selecting sustainable building materials. These tools are limited in use due to the complex nature of sustainability in construction and the environmental characteristics of most materials which are closely related to the sourcing and handling of resources, the way in which they are used, and the care that goes into their detailing and maintenance. The environmental profile of sustainable materials is largely unavailable or incomplete and this is particularly serious in developing countries.

In addition to considering environmental matters in material selection in construction, Abeysundra et al. (2009) suggest that LCA approach for sustainable material selection should also take into consideration of economic and social factors. They developed an evaluation matrix to assist decision-makers in selecting sustainable materials while balancing environmental, economic and social factors in the assessment. Anastaselos et al. (2009) support this view in assessing thermal insulation solutions to include environmental, economic and social aspects.

Florez and Castro-Lacouture (2013) further suggest that factors to be considered in sustainable material selection should not be limited to economic, environmental and social aspects but be inclusive of other subjective factors such as metaphysical and cultural aspects. They have developed an optimization model that integrates both objective and subjective factors in the evaluation process for sustainable material selection. With the widening of the scope of sustainable material selection, the evaluation process has now moved towards a full integration of all aspects emerging during the lifetime of a building and its elements (Anastaselos et al., 2009).

Sustainable material selection is clearly a multi-criteria subject. However, since there is no universally accepted definition of a sustainable building material, there is no clear philosophy that precisely articulates the criteria of materials for sustainability. Esin (2007) and Franzoni (2011) state that sustainable building materials are materials related to resource and energy efficiency in the manufacturing process and that these materials should pollute less and have no negative impact on human health. It becomes apparent that sustainable building materials are related to the following criteria:

- Resource efficiency;

- Energy efficiency (including initial and recurrent embodied energy, and GHG emissions); and

- Pollution prevention (including indoor air quality).

Resource efficiency is all about utilizing the finite resources in the most effective and efficient manner whilst not restricting economic growth on the society. Research indicates that certain resources are becoming extremely rare. Therefore the use of remaining stocks should be treated cautiously, especially where they are known to support threatened habitats, or where these resources are known to be used should take precedence (Halliday, 2008). Most of these rare materials can be substituted by other less rare or renewable materials if they are carefully planned and designed at an early stage (Berge, 2009).

Sustainable building materials should also be designed and manufactured to be long lasting as well as requiring low maintenance throughout their lifetime. This is achieved either by designing for durability or by rehabilitating existing building materials for an extended life. There is good information available on detailing to enhance durability, but materials and components need to 
have worth for reuse, and this may place an emphasis on the specifications for good quality materials in the first instance.

Esin (2007) suggests that resources used for the production of building materials should have been sourced locally in order to save energy and the associated emissions from the transportation of these materials to the project site. Sustainable building materials should be reusable or recyclable in that they can be easily dismantled at the end of their useful life. Gao et al. (2001) state that the production of building materials which contains recycled content is important in terms of conserving natural resources and saving embodied energy. However where recycling contributes to additional and avoidable pollution should be avoided.

Energy efficiency is another important consideration for sustainable building materials. The production and use of energy has become a growing source of environmental concern and research has demonstrated that the production of energy is closely related to the degradation of the environment (Hammond, 2000; Tiwari, 2001). The wide use of fossil fuels, to some degree, has polluted the atmosphere. However, improving the energy efficiency of the building alone may not result in the maximum potential reduction in energy consumption, because there is a substantial portion of energy trapped in the upstream and downstream production of building materials.

The energy use in building materials is often related to the embodied energy embedded in the recovery of raw materials and the manufacturing of building materials together with onsite construction energy and transportation. The embodied energy intensity of building materials varies from region to region and from production plant to production plant, depending on energy sources, technology use and the manufacturing process. The embodied energy of building materials includes initial and recurrent embodied energy. Initial embodied energy relates to the building materials used for construction, whilst recurring embodied energy is required during the operation stage. This refers to the embodied energy used to produce materials for replacement, repair and maintenance over the building's effective life. It is measured during the building's economic life after occupancy.

Both initial and recurrent embodied energy play an important role in the energy efficiency of building materials on a life cycle approach. According to Huberman and Pearlmutter (2008) embodied energy represents between 10 and $60 \%$ of the total energy used during the lifetime of the building. Treloar et al (2001) state that embodied energy is significant because it occurs immediately and the total energy consumed in the production of building materials can equate to, over the life cycle of a building, the temporary requirements for operation energy. Fully identifying the nature and content of the embodied energy intensity will allow designers and building material manufacturers to improve production processes in order to minimise energy consumptions.

Nowadays people spend more than $90 \%$ of their time indoors and therefore indoor conditions have important implications for user health, well-being and performance. (Frontczak \& Wargocki, 2011). It is well-documented from research that building materials play an important role in determining the indoor air quality. The emission of VOCs such as formaldehyde from building materials are regarded as serious problems that affect human health and comfort, and productivity ( $\mathrm{Li} \& \mathrm{Niu}, 2005$; Lee \& Kim, 2012). Therefore sustainable building materials are materials that do not have negative implications for the built and natural environment. Materials that do contain embodied pollution can impact throughout their material lifetime on employees 
during the manufacturing process, to building occupants through off-gassing or leaching in use and eventual pollution through recycling or disposal. Materials that emit low or no carcinogens, reproductive toxicants, or irritants should be used.

Sustainable building materials are about choosing materials manufactured from resourceefficient processes such as choosing materials of a low embodied energy content, using locally provided and renewable energy sources, as well as selecting materials that contribute fewer amounts of GHG emissions to the atmosphere. Commonly used building materials, such as steel, concrete and aluminium, consume energy and release $\mathrm{CO}_{2}$ during the production process. Therefore research into new material production, manufacturing methods, recycling of building materials and using low embodied energy materials has become extremely important. In addition techniques and technologies are improved so that natural resources are minimized and conserved in buildings.

Resource minimization and conservation are considered important aspects in the construction industry. In considering the importance of sustainable building materials in green building design and construction, Berge (2012) suggests switching to the exploitation of smaller deposits of raw materials. This is because small-scale exploitation often contributes less damaging activities to the environment. Halliday (2008) suggests using the "5 Rs" approach to deal with issues related to resource conservation and they refer to refuse, reduce, reuse, recycle and repair.

Refuse refers to setting guidelines on what are and are not acceptable materials in buildings. In 2003, the European Commission released the integrated product policy (IPP) to identify products within the construction sector for products that have the greatest lifetime environmental impact potential. The IPP has led to the development of environmental product declarations (EPD) to communicate the environmental performance of materials from a life cycle perspective. The EPD is being recognised by the USGBC LEED program and is being encouraged by the European Union.

Reuse of building materials deal with a serious resource issue. Reduce relates to the reduction in the use of resources, space or elements. This needs not to undermine from a good design solution such as reducing the amount of mechanical services. It involves the adaptation of existing buildings instead of demolition and reuse of salvaged materials to minimize raw material consumption. The reuse of materials involves the consideration of the material and joining techniques so as to enable the reuse and replacement of components, either in parts or as a whole. Thormark (2000) studied the environmental impacts of reused building materials and the component of a single-family dwelling and concludes that the environmental impacts were about $55 \%$ of the impacts that would have been caused if all materials had been sourced as new.

When the reuse of a component is not possible, it may still be possible to recycle it in whole or in parts. An example includes concrete which is crushed into aggregates for road base. Saghafi and Teshnizi (2011) state that recycling is an effective strategy of reducing environmental impacts in the construction industry as it will help closing the material loop. They developed a method to assess energy savings as a factor for assessing the potential benefits for recycling building materials. This was to assist designers and contractors who could compare and select sustainable materials. Finally, repair is a strategy that aims to reduce a wasteful lifestyle by overhauling and refurbishing to extend the useful life. 


\subsection{Life cycle assessment (LCA) and sustainable building material}

\subsubsection{LCA}

As previously discussed, sustainable building materials play an important role in the environmental performance of a building and impact a building at various stages during the building's life cycle. Therefore the analysis and choosing of sustainable building materials has also been based on a life cycle assessment (LCA).

LCA has a long history and has been used in addressing problems ranging from excessive consumption of global resources, both in terms of construction and building operation, to the pollution of the surrounding environment (Ahn et al., 2010). Sustainability is an important consideration in construction and the concept of sustainability in this area is about creating and maintaining a healthy built environment. At the same time, sustainability is also about focusing on minimizing resources and energy consumption, thereby reducing the damage done to the environment.

There are a great number of tools for environmental assessment of the built environment (Forsberg and von Malmborg 2004), ranging from construction material selection, energy labelling and indoor air quality to a whole building assessment, and then to an urban scale built environment assessment. Reijnders and van Roekel (1999) and Forsberg and von Malmborg (2004) have generally classified current built environment assessment tools into two groups: qualitatively based building rating systems, and quantitative tools using a physical life cycle approach with quantitative input and output data on flows of materials and energy. In both groups there exists a diverse variety of concepts all over the world.

The most appropriate and accepted method used to produce a holistic assessment of the environmental impacts associated with a building and building materials is the LCA (Cole, 1998; Junnila et al., 2006; Horne et al., 2009). Cole (1998) states that LCA approach is the only legitimate basis on which to compare alternative materials, components and services in buildings. Page (2006) suggests that LCA method is a more appropriate means to measure the environmental burden of buildings over other tools as it has the ability to implement a trade-off analysis to achieve a reduction in overall environmental impacts rather than merely a simple shift of impacts.

LCA has been widely used in Europe and the United States, initially for product comparison, but its current application has been extended to include government policy, strategic planning and product design (Kohler \& Moffat, 2003; Scheuer et al., 2003). LCA permits an evaluation of how impacts are generated and distributed across various processes throughout the life cycle where data of environmental qualities was previously lacking (Puettmann \& Wilson, 2005). Ortiz et al. (2009) state that LCA is an important tool for assessing impacts and has been used in the building sector since 1990. The methodology was eventually adopted for the development of building assessment tools around the world.

\subsubsection{Principles and framework}

LCA is a methodology used to analyse complex processes which focus on dealing with the input and output flows of materials, energy and pollutants to and from the environment from a life 
cycle perspective (Perez-Garcia et al., 2005; Puettmann \& Wilson, 2005; Wei et al., 2008; Saghafi \& Teshnizi, 2011). Figure 3.1 demonstrates the process of an LCA study.

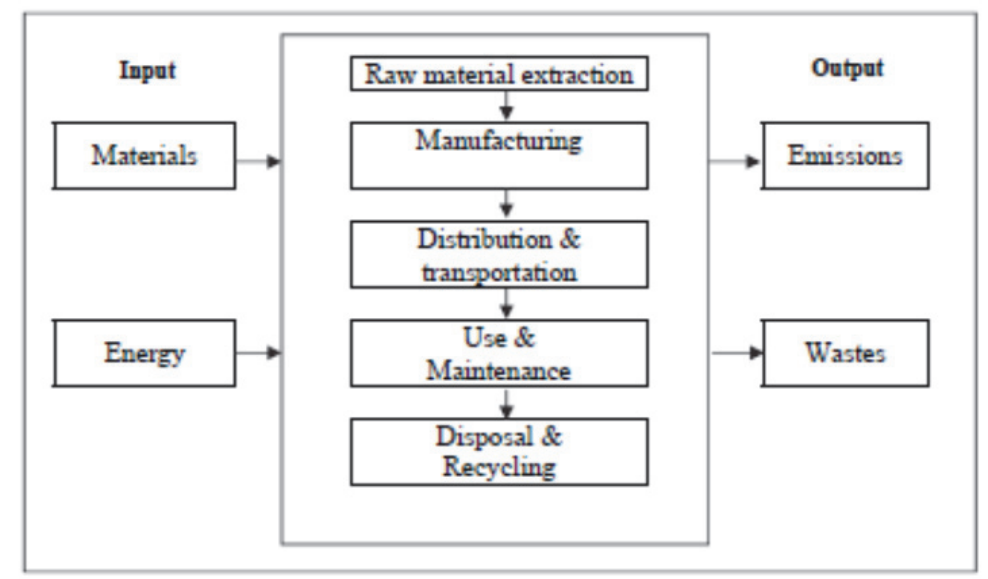

3.1 Input and output flows of materials, energy and pollutants from a life cycle perspective

LCA is best defined as a systematic approach to evaluate the environmental burdens associated with a product, process or activity by identifying and quantifying energy and materials used and wastes released to the environment over the whole life cycle from 'cradle to grave', i.e. from extraction of raw materials to the ultimate disposal of waste from a product, process or activity (Klopffer, 2006; Xing et al., 2008). Therefore the principle objectives of LCA are:

- To quantify and evaluate the environmental performance of a product or a process and to help decision makers choose among alternatives; and

- To provide a basis for assessing potential improvements in the environmental performance of the system so as to modify or design a system in order to decrease its overall environmental impacts. This can be done in an overall sense or targeted to improve specific stages during the life cycle.

The idea for the LCA was conceived in Europe and in the USA in the late 1960s and early 1970s. It was not until the late 1980s and early 1990s that LCA received wider attention in response to increased environmental awareness and concern for energy usage (Azapagic, 1999). There was a need for a more sophisticated approach to analyse complex environmental issues. LCA originated from net energy analysis studies to predict future supplies of raw materials and energy resources over a life cycle approach. During the early studies, energy consumption and efficiency were the main focus and energy-related waste emissions were not considered (Azapagic, 1999). Since the early 1970s, wastes and emissions generated by the production processes were taken into account (Fay \& Treloar, 1998; Treloar et al., 2001).

The LCA methodology was originally developed by the Society of Environmental Toxicology and Chemistry (SETAC, 1993) to improve the science, practice and application of reducing resource consumption and environmental burdens associated with a product, packaging, process or activity (Weir \& Muneer, 1998; Johnstone, 2001). In addition, it enables the identification and quantification of energy and materials used and waste released to the environment over the whole life cycle (Klopffer, 2006). 
In the early 1990 s, concerns over inappropriate claims of LCA results by product manufacturers resulted in action taken by SETAC to develop a standard methodology for conducting LCA studies. In 1997 the International Standards Organization (ISO) published the first ISO 14040 series to standardize the guidelines and principles on the LCA methodology (Perez-Garcia et al., 2005).

In 2006 the ISO 14040 series was revised. The ISO 14040 governs the principles and frameworks, whilst ISO 14044 provides the requirements and guidelines for conducting LCA studies (ISO, 2006a \& b). The ISO approach contained in these Standards is fundamental to the standardization and therefore the generalizability of findings pertaining to all LCA studies and life cycle inventory (LCI) studies.

The Standard states that the overarching aims of LCA include:

- recognizing opportunities to improve environmental performance of products at various stages of their life cycle;

- assisting in decision-making in the industry for strategic planning, priority setting, product design or redesign;

- selecting relevant indicators of environmental performance and developing measurement techniques; and

- marketing e.g. an environmental claim, eco-labelling scheme or environmental product declaration.

In procedural terms and in accordance with the Standard, LCA starts with a definition of the functional unit and then a quantitative inventory of all inputs and outputs is performed. It is followed by a classification and impact assessment and finally, an evaluation of the environmental impact of the system being studied (Bribian et al., 2009). The process of conducting an LCA is well documented and received in the industry as a tool to provide a picture of the interaction of an activity within the environment and to facilitate environmental improvements (Azapagic, 1999).

According to ISO 14040 LCA has four stages (Weir \& Muneer, 1998; Perez-Garcia et al., 2005; Ortiz et al., 2009). The first stage involves developing a goal definition and scope. This stage includes defining study objectives, products and their alternatives, system boundary choice, environmental parameters and a data collection strategy. The second stage is an inventory analysis and this stage includes data collection and treatment, quantifying materials, energy inputs and waste emissions, and preparing inventory tables where a system's material and energy balance is calculated.

The third stage is the life cycle impact assessment (LCIA) that involves classifying the inventory table into impact categories, aggregation within the category, normalisation, weighting different categories where the system's potential environmental impacts are evaluated, and modelling category indicators. The LCIA gives a quantitative assessment of the environmental impacts based on either endpoint (problem-oriented) or midpoint (damage-oriented) approaches (Baumann \& Tillman, 2004). The final stage is an improvement assessment and this stage may involve undertaking a sensitivity analysis to test the results, setting a prioritisation and feasibility assessment to reduce the environmental burden, and formulating recommendations for improvement. 
Drawing from the commentary in Standard, LCA typically does not address the economic or social aspects of a product and the nature of choices and assumptions may be subjective; models used for the inventory analysis or to assess environmental impacts are limited by their assumptions. Furthermore, accuracy may be limited by the accessibility or availability of relevant data, or by data quality. Generally, the information developed in an LCA study should be used as part of a more comprehensive decision process or used to understand the broad or general trade-offs (ISO, 2006a).

\subsubsection{LCA studies}

LCA methodologies have made more complicated and sophisticated the assessment processes for eco-efficient design, and enhanced decision making and reduction of environmental impacts. Within the industry, impacts occur from the extraction and manufacturing of building materials, to the manufacturing processes, operation and eventual disposal at the end of life cycle. LCA is widely acknowledged as a framework systemically analysing and developing strategies to improve the understanding of the environmental impacts of this sector.

LCA has been used in many studies in the building sector as an environmental tool for comparative assessments of whole buildings. Cole (1999) has used the LCA approach to assess the initial embodied energy consumption and GHG emissions of alternative wood, steel and concrete structural systems for buildings with concrete being the highest contributor on both issues. Gustavsson and Sathre (2006) conducted similar research to develop an LCA based methodology to study factors affecting the energy and $\mathrm{CO}_{2}$ balances of concrete and wood frame buildings. Results suggest that the use of wood and wood by-products is an effective means for reducing fossil fuel use and net $\mathrm{CO}_{2}$ emissions into the atmosphere. Thormark (2006) studied how material choice may affect embodied energy levels and the recycling potential in an energy efficient housing project. The conclusion was that having a prolonged lifetime and/or making the choice of materials with less embodied energy levels could considerably reduce the impact.

The LCA has also been used extensively to analyse and compare building materials and systems. Saghafi and Teshnizi (2011), based on the LCA framework, were able to establish the potential recycling energy as a factor for assessing the recycling value of materials by taking into account material selection, construction and deconstruction technologies, and the frequency of recycling.

Wei et al. (2008) and Kellenberge and Althaus (2009) used the LCA to examine the flow of material, energy and pollutants for different building components. Wu et al. (2005) developed an LCA-based method to assess the environmental impacts of building materials. It was based on environmental profiles, in which environmental impacts are categorized and the green tax was used to study the inter-seriousness across different categories.

Haapio and Viitaniemi (2008) used the LCA to analyse how different structural solutions and building materials affected the results of the environmental assessment of a building over the building's life cycle. The research highlighted the importance in the choice of the building's service life. Ip and Miller (2012) conducted an LCA study on the construction of hemp-lime walls and established their life cycle impact on climate change in the UK. The results showed that this hemp-lime wall not only compensated for the GHG emitted during the growing and manufacturing processes but also enabled for the storage of $\mathrm{CO}_{2 \mathrm{e}}$ 
Ardente et al. (2008) conducted an LCA study of a kenaf-fibre insulation board and results indicated that this insulation system has a significant reduction in environmental impacts compared to traditional insulating materials using synthetic materials. Anasaselos et al. (2009) developed an assessment tool to assist designers with the option to select and evaluate building materials to implement thermal insulation solutions and measured their environmental performance, energy efficiency and cost. The outcomes of these studies have a profound impact in utilizing a more environmentally friendly insulation material that can help to reduce emissions to the environment and operation energy consumption.

\subsubsection{LCA Tools}

LCA is a complex and expensive methodology. The LCA framework provides an avenue to obtain quantitative data and indicators to facilitate comparisons to improve material performance for building design and construction. Owing to the subjectivity and complexity, and the varying needs of users, there are LCA-based tools developed to simplify the process of conducting an environmental assessment of building materials. Bayer et al. (2010) state that these tools can be defined as environmental modelling software that develops and presents a life cycle inventory. The impact assessment results from a laborious analytical process. These tools usually follow closely to the ISO standards and other accepted LCA guidelines. These tools take inputs in the form of material take-offs, convert them into mass and attach this mass value to the LCI data available from an LCI database.

Anastaselos et al. (2009), Ortiz et al. (2009) and Bayer et al. (2010) define LCA tools into three levels. Level 1 refers to the tools that are in the form of evaluating environmental performance at a material level. They aim at identifying environmental characteristics of building materials. They can be used as comparison tools and are largely used for materials selection. These tools are found as software packages in various forms of development and use. Commonly-known software tools include GaBi from Germany, SimaPro from the Netherlands, TEAM from France, EDIP from Denmark and LCAiT from Sweden and they provide a framework for evaluating and comparing building products.

Level 2 is related to whole building design decision-making tools, on a life cycle approach. They are software packages used to assess environmental impacts from a whole building approach that take input in terms of building geometry and building assemblies. The result is aggregated for the entire building and presented in the form of environmental impacts. This is due to the different life-cycle stages or the contribution of the building towards a particular impact. They are generally capable of comparing several design options for a building program and are generally helpful during the initial design (Bayer et al, 2010). Some examples of tools include LISA from Australia, Ecoquantum from the Netherlands, Envest from the UK, and ATHENA from Canada. Figure 3.2 below presents the configuration of LCA tools at Level 1 and 2. 


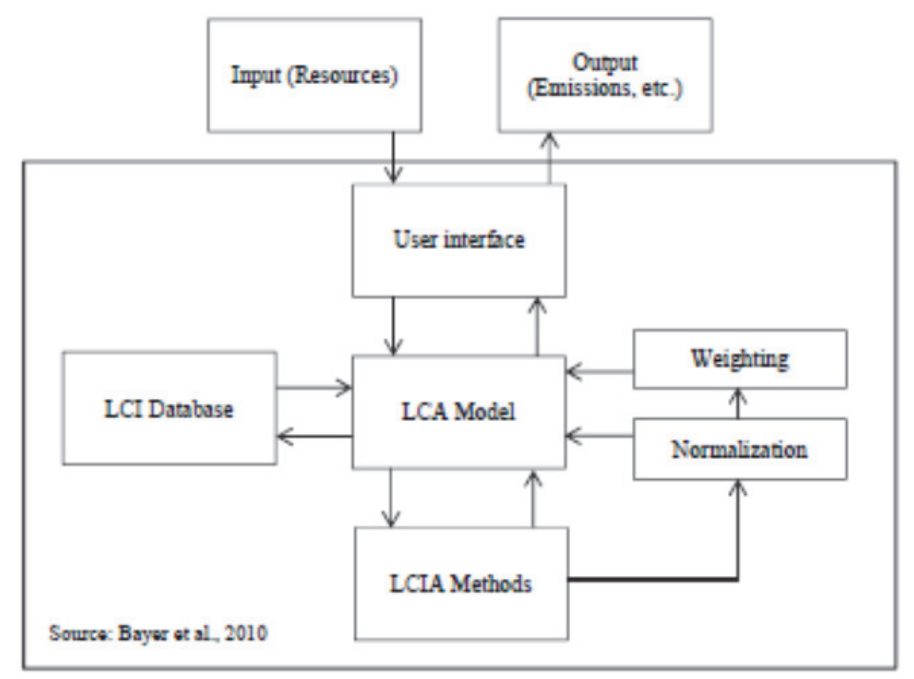

3.2 Levels 1 and 2 LCA software tools

Level 3 is often regarded as the environmental building assessment framework that assesses the performance of a building on a set of pre-determined criteria. The Environmental building assessment framework has been widely used to promote green building design and construction and popular frameworks like Leadership in Energy and Environmental Design (LEED) in the US, Building Research Establishment's Environmental Assessment Method (BREEAM) in the UK, GreenStar in Australia and the internationally developed Green Building Challenge (GBC) (Ding 2012). This Environmental building assessment framework is a rating system aiming at certifying buildings to provide an indication of their environmental performance. The system is based on credits and points. A building is evaluated and points are awarded if the requisites are met. These points are given towards the certification.

Sustainable building material selection takes a role in the environmental building assessment framework but this framework may not be adequate with regards to enhancing the use of sustainable materials (Franzoni, 2011). Encouraging the use of sustainable building materials seems to be one of the biggest challenges facing designers in the environmental building assessment framework. Saghafi and Teshnizi (2011) state that material selection criteria are the most notable failures of building assessment systems in maintaining a clear objective. Additionally, points allocated for sustainable materials selection do not encourage designers and assessors to pay more attention to opt for sustainable building materials as it was only approximately $9 \%, 13 \%$ and $16 \%$ of the total points were allocated respectively in BREEAM, LEED and GreenStar. Figure 3.3 below presents the framework for environmental building assessment tools. 


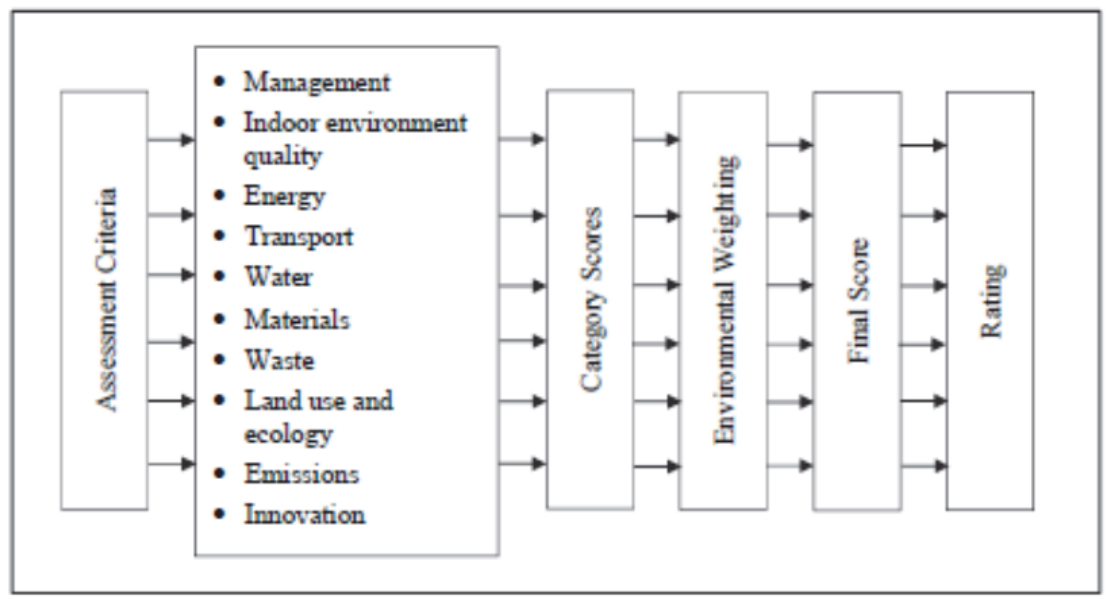

3.3 Framework for Level 3 environmental building assessment tools

\subsubsection{Limitations}

LCA is a systematic and consistent approach for analysing the environmental impacts of building materials. It is becoming a more popular tool used to improve performance from a life cycle perspective. LCA is a complex process as it quantifies and compares inflows of materials and energy and outflows of emissions associated with building materials at different spatial scales and in different contexts (Finnveden et al., 2009). There are limitations for the use of the LCA in the environmental assessment of building materials (IEA, 2004; Keeler \& Burke, 2009). The evaluation process is time-consuming and complex. Despite the great variety of LCA tools, Cole (2010) states that due to data limitations and the large variety of building techniques; these LCA tools are inadequate in modelling and analysing the environmental impacts of all phases in a building.

One of the limitations of LCA is that it is excessively complicated in the calculation applications and high costs and this limitation has restricted its extensive use in the building sector (Bribian et al., 2009; Malmqvist et al., 2010). Proposals were developed to simplify the methodology in a way to improve its current uptake in the construction industry (Liu et al., 2003; Bribian et al., 2009; Kellenberger \& Althaus, 2009; Malmqvist et al., 2010).

LCA involves a life cycle approach in the assessment and therefore the choice of the service life of building materials is critical. However, the choice of the life expectancy of a building material is difficult to determine. The life expectancy is affected by many variables such as user patterns, the maintenance cycle, climatic conditions and detailing and workmanship during design and construction. Haapio and Viitaniemi (2008) state that the impact of the service life of building materials affects the environmental impacts of a building. However this is an area that has been neglected, How the service influences the results of most LCA studies have not often been included.

Although LCA is an ideal tool for analysing the environmental impact of building materials, the method heavily relies on the availability and completeness of LCI data (Finnveden et al., 2009; Bayer et al., 2010). The data of the manufacturing process is also a major issue of data quality as it varies greatly from one region to another and from production plant to another (Esin, 2007; Saghafi \& Teshnizi, 2011). Additionally, the current LCI databases represent conditions in 
industrialized countries which may not be equally applicable to developing countries if they want to conduct LCA studies. There is a large gap in the LCI data in these countries. Therefore the use of these tools and the database in developing countries may not lead to correct decisions without having substantial modifications made to them.

The LCA method is currently focusing on material and energy flows and the associated impacts but not all types of impacts are equally, well covered in a typical LCA (Finnveden et al., 2009). The methodology does not sufficiently assess many sustainability issues such as social and economic concerns, and site-specific impacts such as biodiversity, land use, freshwater sources. In addition, an economic analysis has not been adequately addressed in any of the LCA studies (Abeysundara et al., 2009; Anastaselos et al., 2009). Ortiz et al. (2009) further state that the LCA studies have been undertaken for analysing environmental impacts of building materials but the results of these studies were not fully comparable due to different study scopes and system boundaries (Saghafi \& Teshnizi, 2011).

Saghafi and Teshnize (2011) state that the LCA methodology does not appropriately tackle the close-loop behaviour of materials as it neither addresses whether a product or building can be disassembled and recycled, nor the recyclability of these materials. The framework does not assess correctly when materials are recycled, because recycling in a system occurs where the waste from one production function may become the raw material in another. It is because the occurrence of building material recycling only takes place in the distant future.

LCA is a systematic and consistent approach for analysing the environmental impacts of a building and is becoming a popular methodology to improve performance. The LCA is a useful tool in assessing building related environmental impacts and it will be more effective if it complements with the qualitative assessment tools such as existing environmental building assessment tools to deal with its limitations.

\subsection{Conclusions}

Ecologically sustainable development is a major concern that embodies both environmental protection and management. The concept of ecologically sustainable development is fundamental in developing the goal of sustainable construction. However, the concept itself is somehow vague and broad. Generally speaking, sustainable construction concerns attitudes and judgment to help ensure long-term environmental, social and economic growth in the built environment. In buildings, it involves the efficient allocation of resources, minimum energy consumption, low embodied energy intensity in building materials, reuse and recycling, and other mechanisms to achieve effective and efficient short- and long-term use of natural resources. The improvement in the environmental performance of buildings will indeed encourage greater environmental responsibility and place greater value on the welfare of future generations. Within the context of sustainable construction, the selection and use of sustainable building materials play an important role.

Construction is one of the largest end users of environmental resources and one of the largest polluters of man-made and natural environments. By far the selection of sustainable building materials is the most difficult and challenging task facing the industry. Developing environmental profile of materials and their interaction with the environment require detail analysis environmental impacts on a 'cradle-to-grave' analysis of these materials. Life cycle assessment (LCA) is a comprehensive and systematic method for evaluating the environmental 
impacts of building materials. This method quantifies and compares inflows of materials and energy and outflows of emissions of materials on a life-cycle perspective for possibilities of improvement and providing guidelines for materials selection. The ultimate goal of LCA is to provide users with comprehensive results and enable the evaluation of specific improvement alternatives, based on economic, social and environmental criteria. LCA case studies on commonly used building materials have been done in developed countries but there are insufficient studies in developing countries using local data. Therefore, more LCA studies of building materials are to be developed and used in order that environmental and energy considerations can be implemented worldwide.

\subsection{References}

Abeysundara, Y., Babel, S. \& Gheewala, S. (2009), A matrix in life cycle perspective for selecting sustainable materials for buildings in Sri Lanka, Building and Environment, 44, 997-1004.

Ahn, C., Lee, S.H., Pena-Mora, F. \& Abourizk, S. (2010), 'Toward environmentally sustainable construction processes: The US and Canada's perspective on energy consumption and GHG/GAP emission', Sustainability, 2, 354-370.

Anastaselos, D., Giama, E. \& Papadopoulos, A.M. (2009), 'An assessment tool for the energy, economic and environmental evaluation of thermal insulation solutions', Energy and Buildings, 41, 1165-1171.

Ardente, F., Beccali, M., Cellura, M. \& Mistretta, M. (2008), 'Building energy performance: a LCA case study of kenaf-fibres insulation board', Energy and Building, 40, 1-10.

Azapagic, A. (1999), 'Life cycle assessment and its application to process selection, design and optimization', Chemical Engineering Journal, 37, 1-21

Balderstone, S. (2004), 'Built heritage: a major contributor to environmental, social and economic sustainability', Sustainability Forum Discussion Paper (http://www.heritage.vic.gov.au/admin/file/content101/c6/Sustainability Heritage paper.pdf

Logon: 30/11/2012)

Balaras, C.A., Droutsa, K., Dascalaki, E. \& Kontoyiannidis, S. (2005) 'Heating energy consumption and resulting environmental impact of European apartment buildings', Energy and Buildings, 37, 429-442.

Bayer, C., Gamble, M., Gentry, R., \& Joshi, S. (2010) AIA Guide to building life cycle assessment in practice, The American Institute of Architects, Washington, US.

Bayne, K. \& Taylor, S. (2006) 'Attitudes to the use of wood as a structural material in nonresidential building application: Opportunities for growth', Forest \& Wood Products Australia, Australia.

Baumann, H. \& Tillman, A. (2004) The hitch hiker's guide to LCA: an orientation in life cycle assessment methodology and application, Studentliitteratur, Sweden.

Berge, B. (2009) The ecology of building materials, $2^{\text {nd }}$ Edition, Architectural Press, Elsevier, Oxford, UK.

Bribian, I. Z., Uson, A.A. \& Scarpellini, S. (2009) 'Life cycle assessment in buildings: State-ofthe-art and simplified LCA methodology as a complement for building certification', Building and Environment, 44, 2510-2520.

Bribian, I.Z., Capilla, A.V. \& Uson, A.A. (2011) 'Life cycle assessment of building materials: comparative analysis of energy and environmental impacts and evaluation of the ecoefficiency improvement potential', Building and Environment, 46, 1133-1140.

Cole, R.J. (1998) 'Energy and greenhouse gas emissions associated with the construction of alternative structural systems', Building and Environment, 34 (3), 335-348. 
Cole, R.J. (1999) 'Building environmental assessment methods: clarifying intentions', Building Research and Information, 27(4/5), 230-246.

Cole, R.J. (2010) 'Environmental assessment: shifting scales', In Designing high-density cities for social and environmental sustainability, Edward $\mathrm{Ng}$ (ed), Earthscan, London, 273-282.

Ding, G.K.C. (2012) 'Environmental assessment tools', in Handbook of sustainability management, Nadu, C. N. \& Kuei, C.H. (ed), World Scientific, Singapore, 441-471.

Du Plessis, C. (2007) 'A strategic framework for sustainable construction in developing countries', Construction Management and Economics, 25, 67-76.

Ekanayake, L.L. \& Ofori, G. (2004) 'Building waste assessment score: design-based tool', Building and Environment, 39(7), pp. 851-861.

Esin, T. (2007) 'A study regarding the environmental impact analysis of the building materials production (in Turkey)', Building and Environment, 42, 3860-3871.

Esin, T. \& Cosgun, N. (2007) 'A study conducted to reduce construction waste generation in Turkey', Building and Environment, 42(4), 1667-1674.

Fay, R. \& Treloar, G. (1998) 'Life-cycle energy analysis - A measure of the environmental impact of buildings', Environment Design Guide, Gen 22, Royal Australian Institute of Architects, NSW, 1-7.

Finnveden, G., Hauschild, M.Z., Ekvall, T., Guinee, J., Heijungs, R., Hellweg, S., Koehler, A., Pennington, D. \& Suh, S. (2009) 'Recent developments in life cycle assessment', Journal of Environmental Management, 91, 1-21.

Florez, L. \& Castro-Lacouture, D. (2013) 'Optimization model for sustainable materials selection using objective and subjective factors', Materials and Design, 46, 310-321.

Forsberg, A. \& von Malmberg, F. (2004) 'Tools for environmental of the built environment', Building and Environment, 39, 223-228.

Franzoni, E. (2011) 'Materials selection for green buildings: which tools for engineers and architects?', Procedia Engineering, 21, 883-890.

Frontczak, M. \& Wargocki, P. (2011) 'Literature survey on how different factors influence human comfort in indoor environments', Building and Environment, 46, 922-937.

Gao, W., Ariyama, T., Ojima, T., \& Meier, A. (2001), 'Energy impacts of recycling disassembly material in residential buildings', Energy and Buildings, 33(6), 553-562.

Guggemos, A.A. \& Horvath, A. (2005) 'Comparison of environmental effects of steel-and concrete-framed buildings', Journal of Infrastructure Systems, 11(2), 93-101.

Gustavsson, L. \& Sathre, R. (2006) 'Variability in energy and carbon dioxide balances of wood and concrete building materials', Building and Environment, 41(7), 940-951.

Halliday, S. (2008), Sustainable construction, Butterworth-Heinemann, Sydney, Australia

Hammond, C.P. (2000) 'Energy, environment and sustainable development: a UK perspective', in Institution of Chemical Engineers, 78(B), 304-323.

Haapio, A. \& Viitaniemi, P. (2008), 'A critical review of building environmental assessment tools', Environmental Impact Assessment Review, 28, 469-482.

Horne, R., Grant, T. \& Verghese, K. (2009) Life cycle assessment: principles, practice and prospects, CSIOR Publishing, Collingwood, Vic.

Huberman, N. \& Pearlmutter, D. (2008) 'A life-cycle energy analysis of building materials in the Negev desert', Energy and Buildings, 40, 837-848.

IEA (2004) Life cycle assessment methods for buildings, Annex 31: Energy-Related Environmental Impact of Building, International Energy Agency, US.

Ip, K. \& Miller, K. (2012) 'Life cycle greenhouse gas emissions of hemp-lime wall constructions in the UK, Resources', Conservation and Recycling, 69, 1-9.

ISO (2006a) ISO 14040: Environmental management - Life cycle assessment - Principles and framework, Geneva, International Standards Organization. 
ISO (2006b) ISO 14044: Environmental management - Life cycle assessment - Requirements and guidelines, Geneva, International Standards Organization.

John, G., Clements-Croome, D. \& Jeronimidis, G. (2005) 'Sustainable building solutions: a review of lessons from the natural world', Building and Environment, 40, 319-328.

Johnstone, I.M. (2001) 'Energy and mass flows of housing: a model and example', Building and Environment, 36, 27-41.

Junnila, S., Horvath, A. \& Guggemos, A. (2006) 'Life-cycle assessment of office buildings in Europe and the United States', Journal of Infrastructure Systems, 12(1), 10-17.

Keeler M. and Burke B. (2009) Fundamentals of integrated design for sustainable buildings, John Wiley \& Sons, Inc., New Jersey

Kellenberger, D. \& Althaus, H. (2009) 'Relevance of simplifications in LCA of building components', Building and Environment, 44, 818-825.

Klopffer, W. (2006) 'The role of SETAC in the development of LCA', International Journal of Life Cycle Analysis, 11(1), 116-122.

Kohler, N. \& Moffatt, S. (2003) Life-cycle analysis of the built environment, UNEP Industry and environment, sustainable building and construction, UNEP, April/September, 17-21.

Lee, Y. \& Kim, H. (2012) 'The effect of temperature on VOCs and carbonyl compounds emission from wooden flooring by thermal extractor test method', Building and Environment, 53, 95-99.

Li, F. \& Niu, J. (2005) 'Simultaneous estimation of VOCs diffusion and partition coefficients in building materials via inverse analysis', Building and Environment, 40, 1366-1374.

Li, X., Zhu, Y. \& Zhang, S. (2010) 'An LCA-based environmental impact assessment model for construction processes', Building and Environment, 45, 766-775.

Liu, L., Liu, Z. \& Fung, R. (2003) 'The most of the most ... Study on a new LCA method', Proceedings of the IEEE, pp. 177-182.

Malmqvist, T., Glaumann, M., Scarpelline, S., Zabalza, I., Aranda, A., Llera, E. \& Diaz, S. (2011) 'Life cycle assessment in buildings: The ENSLIC simplified method and guidelines', Energy, 36(4), 1900-1907.

Mokhlesian, S. and Holmen, M. (2012) 'Business model changes and green construction processes', Construction Management and Economics, iFirst, 1-15.

Ortiz, O., Castells, F. \& Sonnemann, G. (2009) 'Sustainability in the construction industry: a review of recent developments based on LCA', Construction and Building Materials, 23, 28-39.

Page, I. (2006) Timber in government buildings - cost and environmental impact analysis, BRANZ Publication.

Perez-Garcia, J., Lippke, B., Briggs, D., Wilson, J.B., Bowyer, J. \& Meil, J. (2005) 'The environmental performance of renewable building materials in the context of residential construction', Wood and Fibre Science, 37, 3-17.

Puettmann, M.E. \& Wilson, J.B. (2005) 'Life-cycle of wood products: cradle-to-grate LCI of residential wood building materials', Wood and Fibre Science, 37, 18-29.

Ramesh, T., Prakash, R. \& Shukla, K.K. (2010) 'Life cycle energy analysis of buildings: an overview', Energy and Buildings, 42(10), 1592-1600.

Reijnders, L. \& van Roekel, A. (1999) 'Comprehensive and adequacy of tools for the environmental improvement of buildings', Journal of Cleaner Production, 7, 221-225.

Saghafi, M.D. \& Teshnizi, Z.S.H. (2011) 'Recycling value of building materials in building assessment systems', Energy and Buildings, 43, 3181-3188.

Scheuer, C., Keoleian, G.A. \& Reppe, P. (2003) 'Life cycle energy and environmental performance of a new university building: Modelling challenges and design implications', Energy and Buildings, 35, 1049-1064. 
SETAC (1993) Guidelines for life cycle assessment: a code of practice, Society of Environmental Toxicology and Chemistry, Washington DC, US.

Spiegel, R. \& Meadows, D. (1999) Green building materials: a guide to product selection and specification, John Wiley \& Sons Inc., New York.

Sterner, E. (2002) 'Green procurement of buildings: A study of Swedish clients' considerations', Construction Management and Economics, 20, 21-30.

Sturges, J. (1999) 'Towards sustainable construction materials selection for the new millennium', Proceedings of COBRA 1999, The challenge of change: Construction and building for the new millennium, 1-2 September, University of Salford, Salford

Thormark, C. (2000) 'Environmental analysis of a building with reused building materials', Building Research \& Information, 28(3), 176-183.

Thormark, C. (2006) 'The effect of materials choice on the total energy need and recycling potential of a building', Building and Environment, 41, 1019-1026.

Tiwari, P. (2001) 'Energy efficiency and building construction in India', Building and Environment, 36, 1127-1135.

Treloar, G. J., Love, P.E.D. \& Faniran, O.O. (2001) 'Improving the reliability of embodied energy methods for project life-cycle decision making', Logistics Information Management, 14(5/6), 303-317.

Wei, H.L., Ni, J. R. \& Xu, N. (2008) 'Energy, material and pollutant intensity analysis in the life cycle of walling materials', Energy Sources, Part A, 30, 1367-1381.

Weir, G. \& Muneer, T. (1998) 'Energy and environmental impact analysis of double-glazed windows', Energy Conversion Management, 39(3/4), 243-256.

Wu, X., Zhang, Z. \& Chen, Y. (2005) 'Study of the environmental impacts based on the green tax - applied to several types of building materials', Building and Environment, 40(2), 22737.

Xing, S., Xu, Z. \& June, G. (2008) 'Inventory analysis of LCA on steel- and concreteconstruction office buildings', Energy and Buildings, 40, (7), 1188-1193. 